Journal of Computer Science 7 (9): 1330-1334, 2011

ISSN 1549-3636

(C) 2011 Science Publications

\title{
Koch Curves: Rewriting System, Geometry and Application
}

\author{
Mamta Rani, Riaz Ul Haq and Norrozila Sulaiman \\ Faculty of Computer Systems and Software Engineering, \\ University Malaysia Pahang, 26300, \\ Gambang, Kuantan, Malaysia
}

\begin{abstract}
Problem statement: Recently, new Koch curves have been generated by dividing the initiator into three unequal parts. There is no formal rewriting system to generate such kind of curves. Approach: It is required to measure the new changed geometrical properties. Generalized rewriting systems for the new Koch curves have been developed. Results: New formulas have been given to measure their geometrical properties. Conclusion/Recommendations: The geometrical properties of new Koch curves make them more suitable as antennas in wireless communication than the conventional Koch curve.
\end{abstract}

Key words: Koch curve, superior koch curve, koch loop, rewriting system, fractal antenna, fractal dimension, rewriting rules, fundamental mathematical properties, natural number, superior fractals, multi-band characteristics

\section{INTRODUCTION}

The classical Koch curve is, mathematically, continuous everywhere but differentiable nowhere. It is an example of bounded curve of infinite length (Schroeder, 2009; Falconer, 2003). Koch snowflake curve is used as a fractal antenna. Nathan (2005) described the importance of fractal antennas explicitly for wireless technologies with emphasis to military services. For a detailed study on Koch fractal antenna and related various new findings, one may refer to (Elkamchouchi and Nasr, 2007; Ghatak et al., 2009; Kordzadeh and Kashani, 2009; Krishna et al., 2009; Mirzapour and Hassani, 2009; Song et al., 2008; Werner and Suman, 2003; Zhang and Kishk, 2006) and several cross references thereof. McClure (2008) has discussed the vibration modes of a drum shaped like a Koch snowflake. Epstien and Adeeb (2008) derived stiffness of the Koch curve. Jibrael et al. (2008) simulated quadratic Koch antenna and explored its antenna properties. Further, Vinoy et al. (2002) presented a new way of generation of variants of a Koch curve by varying indentation angle and gave a formula to calculate their fractal dimension and studied the impact of fractal dimension in the design of multi-resonant fractal antennas (Vinoy et al., 2004). Generated new Koch curves as new examples of superior fractals by dividing the initiator into three unequal parts. A comprehensive review of literature on superior fractals, which are constructed using superior iterates, is given by Singh et al. (2011).

The purpose of this study is to develop rewriting rules for superior Koch curves and suggest formulas for calculation of their fundamental mathematical properties.

Preliminaries: Construction of the Koch curve (Fig. 1) is well known. It can be expressed by following rewrite system (L-system)

(http://en.wikipedia.org/wiki/Koch_curve):

\section{Alphabet : F \\ Cons $\tan \mathrm{t}:+,-$}

Axiom : $\mathrm{F}$

Production rule $: \mathrm{F} \rightarrow \mathrm{F}+\mathrm{F}--\mathrm{F}+\mathrm{F}$

Here, F means "draw forward", + means "turn left $60^{\circ}$ " and - means "turn right $60^{\circ}$.

To draw a Koch snowflake curve, the Prod. Rule 1 is applied on axiom "F - - F - - F".

Rewriting system for koch curves: In this section, we develop general production rules to draw superior Koch curves. We divide the production rules for Koch curves at different scaling factors into two parts. All the symbols used in the following rewriting systems carry similar meanings as in that of Koch

Corresponding Author: Mamta Rani, Faculty of Computer Systems and Software Engineering University Malaysia Pahang, 26300, Gambang, Kuantan, Malaysia 
curve. We use the same initiator, as shown in Fig. 1a, in all the generations.

Case 1: Koch curves at scaling factor $S=\frac{1}{n}$, where $\mathrm{n}$ is an odd number.

Let $S=\frac{1}{5}$, then one of the possible Koch curves is shown in Fig. 2. The following is the rewriting system for such a Koch curve:

Figure 2 Koch middle one-fifth curve for $(\mathrm{r} 1, \mathrm{r} 2$, $\mathrm{r} 3)=(2 / 5,1 / 5,2 / 5)$ with its initiator:

Scaling factor: Alphabet : $\mathrm{F}$

Constan $\mathrm{t}:+,-$

Axiom : $\mathrm{F}$

Production rule $\mathrm{F} \rightarrow \mathrm{FF}+\mathrm{F}--\mathrm{F}+\mathrm{FF}$

At $S=\frac{1}{7}$, rewriting system for Koch middle oneseventh curve is as follows:

Scaling factor :Alphabet : F

Cons $\tan \mathrm{t}:+,-$

Axiom : $\mathrm{F}$

Production rule $: \mathrm{F} \rightarrow \mathrm{FFF}+\mathrm{F}--\mathrm{F}+\mathrm{FFF}$

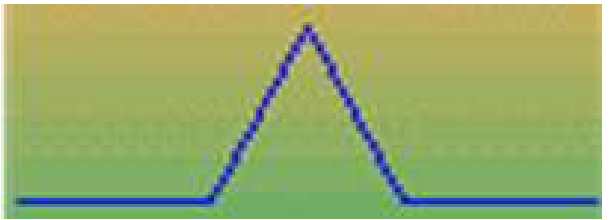

(a)

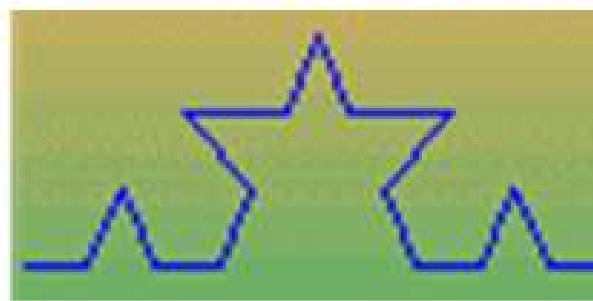

(b)

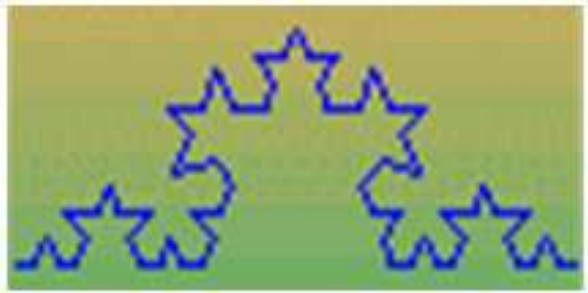

(c)

Fig. 1: Iterative construction of koch curve
The general rewriting system for Koch curves at $\mathrm{S}=1 / \mathrm{n}$, where $\mathrm{n}=3,5,7,9, \ldots$, which can be derived from Prod. Rule 1, 2 and 3 is as follows:

Scaling factor $\mathrm{S}=\frac{1}{\mathrm{n}}$, where $\mathrm{n}$ is an odd natural number and $\mathrm{n} \geq 3$ :

Alphabet : F

Constant $:+,-$

Axiom : $\mathrm{F}$

Production rule $\mathrm{F} \rightarrow((\mathrm{n}-1) / 2) \mathrm{F}+\mathrm{F}--\mathrm{F}+((\mathrm{n}-1) / 2) \mathrm{F}$

Case 2: Koch curves at scaling factor $S=1 / n$, where $n$ is an even number.

Let the scaling factor be $1 / 4$, then rewriting system for the two possible Koch middle one-fourth curves (see the generators in Fig. 3) is given below.

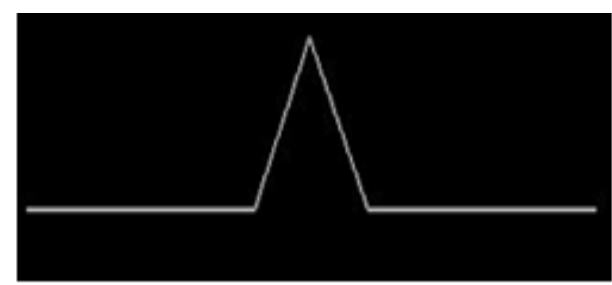

(a)

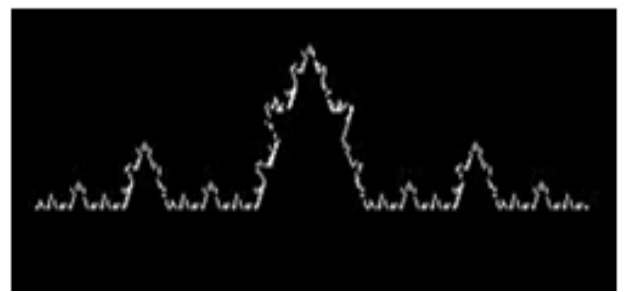

(b)

Fig. 2: Koch middle one-fifth curve for $(\mathrm{r} 1, \mathrm{r} 2, \mathrm{r} 3)=$ $(2 / 5,1 / 5,2 / 5)$ with its initiator

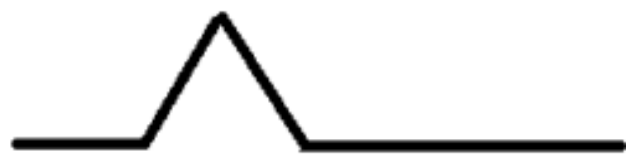

(a)

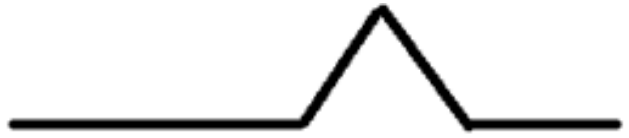

(b)

Fig. 3: Generators of two possible Koch middle one-fourth curves (a) Generator at $(\mathrm{r} 1, \mathrm{r} 2, \mathrm{r} 3)=(1 / 4,1 / 4,1 / 2)$ (b) Generator at $(\mathrm{r} 1, \mathrm{r} 2, \mathrm{r} 3)=(1 / 2,1 / 4,1 / 4)$ 


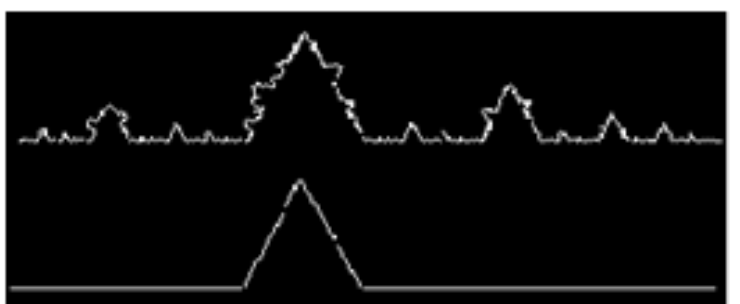

(a)

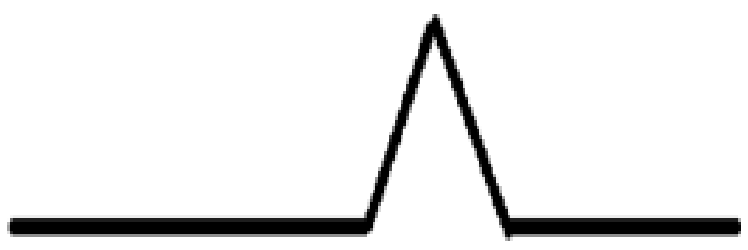

(b)

Fig. 4: Koch middle one-sixth curve (a) At generator $(\mathrm{r} 1, \mathrm{r} 2, \mathrm{r} 3)=(1 / 3,1 / 6,1 / 2)(\mathrm{b})$ At generator $(\mathrm{r} 1$, $\mathrm{r} 2, \mathrm{r} 3)=(1 / 2,1 / 6,1 / 3)$

Scaling factor: $S=\frac{1}{4}$ Alphabet: $F$ :

Cons tan $\mathrm{t}:+,-$

Axiom : $\mathrm{F}$

Production rule $\mathrm{F} \rightarrow \mathrm{F}+\mathrm{F}--\mathrm{F}+\mathrm{FF}$

or $\mathrm{F} \rightarrow \mathrm{FF}+\mathrm{F}--\mathrm{F}+\mathrm{F}$

At the scaling factor $S=\frac{1}{6}$, rewriting system for two possible Koch middle one-sixth curve (Fig. 4) is as follows:

Scaling factor :

Alphabet :F

Constan $\mathrm{t}:+,-$

Axiom : $\mathrm{F}$

Production rule $\mathrm{F} \rightarrow \mathrm{FF}+\mathrm{F}--\mathrm{F}+\mathrm{FFF}$

or $\mathrm{F} \rightarrow \mathrm{FFF}+\mathrm{F}--\mathrm{F}+\mathrm{FF}$

The general rewriting system for Koch curves at $\mathrm{S}=\frac{1}{\mathrm{n}}$, where $\mathrm{n}=4,6,8,10, \ldots$, which can be derived from Prod. Rule 5 and 6 is as follows:

Scaling factor: $\mathrm{S}=\frac{1}{\mathrm{n}}$, where $\mathrm{n}$ is an even natural number and $n \geq 4$ :

\section{Alphabet : F}

Constan $\mathrm{t}:+,-$

Axiom : $\mathrm{F}$

Production rule $\mathrm{F} \rightarrow(\mathrm{n} / 2-1) \mathrm{F}+\mathrm{F}--\mathrm{F}+((\mathrm{n} / 2) \mathrm{F}$

OrF $\rightarrow(\mathrm{n} / 2-1) \mathrm{F}+\mathrm{F}--\mathrm{F}+((\mathrm{n} / 2) \mathrm{F}$

Applications to fractal antenna: Authors have generated superior Koch curves at scaling factors $\mathrm{S}=$ $1 / n$, for $n \geq 4$. Koch loop can be generated by applying Prod. Rule 4 or 7 on the axiom "F - F - - F". Following are some of the geometric features of a Koch loop. Here, $r$ denotes the radius of the circle which accommodates the Koch loop.

The general formula to calculate the area of a Koch loop is given by:

Area $_{\text {KochLoop }}=\frac{3 \sqrt{3}}{4} \mathrm{r}^{2}\left(1+\frac{3}{\mathrm{n}^{2}-4}\right), \mathrm{n} \in \mathrm{N}$ and $\mathrm{n} \geq 3$

Therefore:

$$
\begin{aligned}
& \text { Area }_{\text {KochLoop }}=\lim _{n \rightarrow \infty} \frac{3 \sqrt{3}}{4} r^{2}\left(1+\frac{3}{n^{2}-4}\right) \\
& =\frac{3 \sqrt{3}}{4} r^{2}
\end{aligned}
$$

Thus smaller the scaling factor, lesser the area of the Koch loops.

The general formula to calculate the perimeter of a Koch loop is given by:

Perimeter $_{\text {Kochloop }}=3 \sqrt{3} \mathrm{r}+\frac{9 \sqrt{3}}{\mathrm{n}} \mathrm{r}$

$\left((4 / 3)^{\mathrm{m}}-1\right), \mathrm{m}, \mathrm{n} \in \mathrm{N}$ and $\mathrm{n} \geq 3$

Where $\mathrm{m}$ is the total number of iterations.

\section{Considering:}

$\lim _{m \rightarrow \infty} 3 \sqrt{3} r \frac{9 \sqrt{3}}{n} r\left((4 / 3)^{m}-1\right)$

We see that Perimeter $_{\text {KochLoop }}=\infty$

Theoretically, a Koch loop can accommodate wire of infinite length. However, with the reducing scaling factor, growth rate of the perimeter decreases. 


\section{J. Computer Sci., 7 (9): 1330-1334, 2011}

The general formula to calculate the dimension of a Koch curve is given by:

$$
\text { Dimension }_{\text {Kochaure }}=\frac{\log (\mathrm{n}+1)}{\log \mathrm{n}}, \mathrm{n} \in \mathrm{N} \text { and } \mathrm{n} \geq 3
$$

From (10), it can be calculated that the dimension of Koch curves at $n=4,5$ and 6 is approximately 1.16, 1.113 and 1.086 respectively. According to (Vinoy et al., 2004; Song et al., 2008), since fractal antennas having smaller dimensions show better multiband characteristics, Koch antennas at $S=\frac{1}{n}$, for $n \geq 4$, shall exhibit better multiband characteristics.

Theoretically, superior Koch loops, generated at $\mathrm{S}=\frac{1}{\mathrm{n}}$, for $\mathrm{n} \geq 4$, are more suitable as antennas than the Koch antenna at $\mathrm{S}=\frac{1}{3}$, as they are more compact in size (cf. (8)) and can accommodate long length of wire (cf. (9)) and therefore will have better multiband characteristics due to smaller fractal dimension (cf. (10)).

\section{CONCLUSION}

Following formulas have been derived in this study: Rewriting system for superior Koch curves at.

Scaling factor: $s=1 / n$, where $n$ is an odd natural number and $\mathrm{n} \geq 3$ :

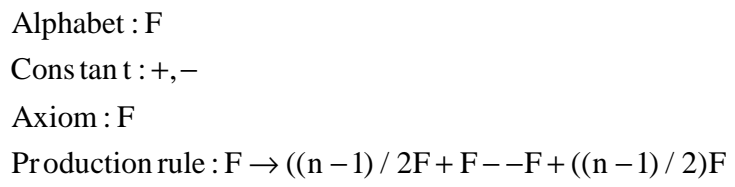

Scaling factor: $s=1 / n$, where $n$ is an even natural number and $n \geq 4$ :

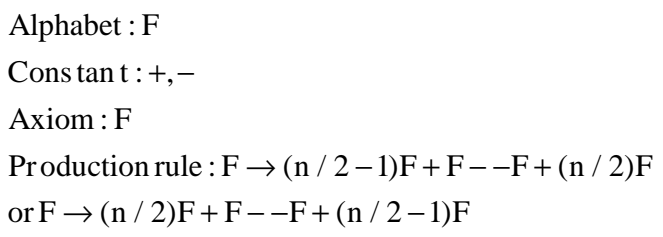

Geometrical properties of a superior Koch loop is given by:

$$
\begin{aligned}
& \text { Area } \left._{\text {KoochLoop }}=\frac{3 \sqrt{3}}{4} \mathrm{r}^{2}\left(1+\frac{3}{\mathrm{n}^{2}-4}\right), \forall \mathrm{n} \in \mathrm{N} \text { and } \mathrm{n} \geq 3 ;\right) \\
& \text { Permiter }_{\text {KoochLop }}=3 \sqrt{3} \mathrm{r}+\frac{9 \sqrt{3}}{\mathrm{n}} \mathrm{r}\left((4 / 3)^{\mathrm{m}}-1\right), \\
& \forall \mathrm{m}, \mathrm{n} \in \mathrm{N} \text { and } \mathrm{n} \geq 3 ; \\
& \text { Dimension }_{\text {KochLoop }}=\frac{\log (\mathrm{n}+1)}{\log \mathrm{n}}, \forall \mathrm{n} \in \mathrm{N}, \mathrm{n} \geq 3 ;
\end{aligned}
$$

Here, $\frac{1}{n}$ is the scaling factor and $r$ is the radius of the circle which accommodates the Koch loop.

Fractal antenna is preferred over circular antenna because it is compact and has multiband characteristics. Theoretically, a superior Koch antenna, generated at $\mathrm{S}=\frac{1}{\mathrm{n}}, \mathrm{n} \geq 4$, are more suitable as an antenna than the Koch antenna at $\mathrm{S}=\frac{1}{3}$, as they are more compact (Result 2(i)), can accommodate long length of wire (Result 2(ii)) and will have better multiband characteristic due to smaller fractal dimension (Result 2(iii)).

\section{ACKNOWLEDGMENT}

Researchers would like to thank University Malaysia Pahang for providing fund for this research.

\section{REFERENCES}

Epstien, M. and S.M. Adeeb, 2008. The stiffness of self-similar fractals. Int. J. Solids Struct., 45: 32383254. DOI: 10.1016/J.IJSOLSTR.2008.01.022

Elkamchouchi, H. and M.A. Nasr, 2007. 3D-Fractal rectangular Koch dipole and Hilbert dipole antennas. Proceedings of the IEEE International Conference on Microwave and Millimeter Wave Technology, Apr. 18-21, IEEE Xplore Press, Builin, 1-4. DOI: 10.1109/ICMMT.2007.381294

Falconer, K.J., 2003. Fractal Geometry: Mathematical Foundations and Applications. 2nd Edn., Wiley, Chichester, ISBN: 0470848626, pp: 337.

Ghatak, R., D.R. Poddar and R.K. Mishra, 2009. A moment-method characterization of V-Koch fractal dipole antennas. Int. J. Electron. Commun., 63: 279-286. DOI: 10.1016/J.AEUE.2008.01.010

Jibrael, F.J., F.F. Shareef and W.S. Mummo, 2008. Small size and dual band of a quadratic Koch dipole fractal antenna design. Am. J. Applied Sci. 5: 1804-1807. DOI: 10.3844/AJASSP.2008.1804.1807 
Kordzadeh, A. and F.H. Kashani, 2009. A new reduced size microstrip patch antenna with fractal shaped defects. Prog. Electromag. Res. B., 11: 29-37. DOI: 10.2528/PIERB08100501

Krishna, D.D., M. Gopikrishna, C.K. Anandan, P. Mohanan and K. Vasudevan, 2009. Compact wideband Koch fractal printed slot antenna. IET Microw. Antennas Propag., 3: 782-789. DOI: 10.1049/iet-map.2008.0210

McClure, M., 2008. Images of a vibrating Koch drum. Comput. Graphics, 32: 711-715. DOI: 10.1016/J.CAG.2008.05.007

Mirzapour, B. and H.R. Hassani, 2009. Size reduction and bandwidth enhancement of snowflake fractal antenna. IET Microw. Antennas Propag., 2: 180187. DOI: 10.1049 /iet-map:20070133

Nathan, C., 2005. Fractals' New Era in Military Antenna Design. Defense Electronics. http://preview.rfdesign.com/mag/508RFDSF1.pdf

Schroeder, M., 2009. Fractals, Chaos, Power Laws: Minutes from an Infinite Paradise. 1st Edn., Dover Publications, Mineola, ISBN: 0486472043, pp: 448.

Singh, S.L., S.N. Mishra and W. Sinkala, 2011. A new iterative approach to fractal models. Commun. Nonlinear Sci. Numer. Simulat. DOI: 10.1016/j.cnsns.2011.06.014
Song, X.D., J.M. Fu and W. Wang, 2008. Design of a miniaturized dual band Koch fractal boundary microstrip antenna. Proceedings of the China Japan Joint Microwave Conference, Sept. 10-12, IEEE Xplore Press, Shanghai, pp: 282-284. DOI: 10.1109/CJMW.2008.4772426

Vinoy, K.J., K.A. Jose and V.K. Varadan, 2002. Multiband characteristics and fractal dimension of dipole antennas with Koch curve geometry. Proceedings of the Antennas and Propagation Society International Symposium (APSIS'02), IEEE Xplore Press, pp: 106-109. DOI: 10.1109/APS.2002.1016937

Vinoy, K.J., J.K. Abraham and V.K. Varadan, 2004. Impact of fractal dimension in the design of multiresonant fractal antennas. Fractals, 12: 55-66. DOI: 10.1142/S0218348X04002288

Werner, D.H. and G. Suman, 2003. An overview of fractal antenna engineering research. IEEE Antennas Propag. Mag., 45: 38-57. DOI: 10.1109/MAP.2003.1189650

Zhang, Y. and A.A. Kishk, 2006. Analysis of dually polarized fractal antennas. Proceedings of the IEEE Antennas Propagation Society International Symposium, Jul. 9-14, IEEE Xplore Press, Albuquerque, NM, pp: 2041-2044. DOI: 10.1109/APS.2006.1710981 